\title{
Return to the labour market in schizophrenia and other psychoses - a register- based Northern Finland Birth Cohort 1966 study
}

Tuomas Majuri $^{1} \cdot$ Marianne Haapea $^{1,2,3} \cdot$ Hanna Huovinen $^{1} \cdot$ Tanja Nordström $^{1,2,4}$. Leena Ala-Mursula ${ }^{1} \cdot$ Matti Penttilä $^{1}$ · Kari-Pekka Martimo ${ }^{5}$ Jouko Miettunen ${ }^{1,2} \cdot$ Erika Jääskeläinen $^{1,2,3}$

${ }^{1}$ Center for Life Course Health Research, University of Oulu, Oulu, Finland.

${ }^{2}$ Medical Research Center Oulu, Oulu University Hospital and University of Oulu, Oulu, Finland.

${ }^{3}$ Department of Psychiatry, Oulu University Hospital, Oulu, Finland.

${ }^{4}$ Northern Finland Birth Cohorts, Infrastructure for Population Studies, University of Oulu, Oulu, Finland.

${ }^{5}$ Ilmarinen Mutual Pension Insurance Company, Helsinki, Finland.

Corresponding author:

BMed Tuomas Majuri,

Center for Life Course Health Research, Faculty of Medicine

P.O.BOX 5000, 90014, University of Oulu, Finland

email tuomas.majuri@student.oulu.fi

We thank all cohort members and researchers. We also wish to acknowledge the work of the NFBC project center. 


\section{$\underline{\text { Abstract }}$}

Purpose The prospects and predictors of returning to the labour market after long-term work disability in psychoses are unclear. Our aim was to study the proportion and characteristics of persons with schizophrenia and other psychoses who return to the labour market after receiving a disability pension.

Methods In this 50-year follow-up study in the Northern Finland Birth Cohort 1966 (NFBC1966), national registers on demographics, care, and disability pensions were used to detect and characterize individuals who had been on a disability pension for psychiatric reasons. We compared individuals with schizophrenia (SZ, n=223) or other psychoses $(O P, n=200)$ to those with non-psychotic psychiatric disorders (NP, n=1815) regarding demographics and end of pension by crosstabulations and logistic regression.

Results Of the 170 (74\%) persons with SZ who had been on disability pension for a psychiatric reason, 15 (9\%) returned to the labour market. Corresponding percentages were $19 \%$ for OP and $28 \%$ for NP. In SZ, being married, a later onset age of psychosis, and better school performance, and in OP and NP, having children predicted returning to the labour market. In all groups, a shorter length of the latest disability pension associated with returning to the labour market.

Conclusion Although rare, it is possible to return to the labour market after a disability pension due to psychosis. Factors predicting a return to the labour market could be taken into account when planning rehabilitation.

Keywords Schizophrenia $\cdot$ Psychosis $\cdot$ Recovery $\cdot$ Labour market $\cdot$ Disability pension 


\section{$\underline{\text { Introduction }}$}

Individuals with schizophrenia often have poor social functioning [1] and a high risk of being outside the labour market [2]. Many European studies report employment rates between $10 \%$ and $20 \%$ among individuals with schizophrenia [3]. Based on a recent, Finnish nationwide study, 89-94\% of persons with schizophrenia are outside the labour force between ages 25 and 52 and they are also at an increased risk of not completing any secondary or higher education [4]. In the Northern Finland Birth Cohort 1966 (NFBC1966) almost 60\% of persons with schizophrenia received disability pension during the first 10 years of illness [5], and in another Finnish study 89\% of people with schizophrenia or schizoaffective disorder were on permanent or fixed-term disability pension [6]

A recent review highlighted the small but existing potential for clinical and functional recovery from schizophrenia [7]. Whether recovery is possible to the extent of allowing a return to the labour market from a disability pension, has not been studied. In the literature, typically a return to existing part- or full-time employment contract has been studied during a follow-up time of a few weeks to several weeks [8]. Longitudinal studies on return to work (RTW) in schizophrenia and other psychoses are only a few $[9,10]$, showing that persons with psychosis have lower employment rates after longterm work disability compared to other psychiatric disorders. Virtanen et al. [10] studied psychiatric work disability as long-term sick leave ( $\geq 90$ days) or the receipt of a disability pension among public-sector employees in a prospective cohort study with a mean follow-up of 6.3 years. They found that $46 \%$ of people with schizophrenia, schizotypal, and delusional disorders were able to return to work after a disability episode and $41 \%$ of them within one year. Higher socioeconomic status predicted RTW in schizophrenia and related disorders [10]. Joensuu et al. [9] found that $40 \%$ of people with psychotic disorder were employed at any time during the 5.6 years of follow-up, and that $13 \%$ were employed at the end of the follow-up after a new-onset of a fixed-term disability pension.

While we know that occupational functioning among people with schizophrenia is low and a disability pension is common, we know little about persons on a disability pension who are able to return to the labour market and its potential predictors. This information, however, would be, important for patients, clinicians, and society.

The first aim of this follow-up study was to analyse in a general population sample until the age of 50 years, how many persons with psychosis, and especially schizophrenia, return to the labour market after a disability pension, as compared to persons with other psychiatric illnesses. The second aim was to characterize the persons who can return to the labour market.

\section{Methods}

\section{Sample}

The study was based on the Northern Finland Birth Cohort 1966 (NFBC1966), which is an unselected, general population sample based on 12,058 live-born children with an expected date of birth in 1966 in the provinces of Oulu and Lapland [11]. The cohort members have been followed-up with data collections at different ages, including national register data, and hospital records (https://www.oulu.fi/nfbc/). In this 50-year follow-up study, we only use data from various registers until the end of 2016, as detailed below.

Psychiatric diagnoses of NFBC1966 members were gained from national registers. The Care Register for Health Care (CRHC) was used to find diagnoses of all general and psychiatric hospitalizations from birth until the end of 2016 and visits to specialized outpatient care in 1998-2016. The Register of Primary Health Care Visits (2011-2016) was used to find outpatient diagnoses in primary care. The data on lifetime diagnoses of individuals were complemented using register information of the Social Insurance Institution of Finland (SII) on received special drug reimbursement (1974-2005), diagnoses for receiving sickness allowances (1974-1999), diagnoses for receiving disability pensions (1981-1998), and information of the Finnish Centre for Pensions (FCP) on diagnoses for receiving disability pensions (1974-2016) [12].

Cohort members diagnosed with any mental disorder based on different versions of the International Classification of Diseases (ICD-8: 290-308, 7092; ICD-9: 290-316; ICD-10: F00-F99) until 2016 were searched from the registers. Individuals with psychiatric disorder were included, excluding those with a diagnosis of organic disorder (e.g. ICD-10 codes F00-F09). The focus was on individuals with schizophrenia and other psychoses, and for comparison purposes, we extracted data concerning those with non-psychotic mental disorder. When setting the diagnosis for the subject (Table 1), we used a hierarchical system, in which the life-time diagnosis for each subject was the one that had the highest position in the hierarchy. The hierarchical order of diagnoses was from the most severe to less severe: schizophrenia, other psychosis, non-psychotic disorders. This hierarchy has been used in previous studies of NFBC1966 [13]. Please see online supplement 1 for further details. We detected 229 (1.9\% of the original NFBC1966 sample) subjects with schizophrenia 
(SZ), 205 (1.7\%) with other psychoses (OP), and 1877 (15.6\%) with non-psychotic (and non-organic) psychiatric disorders (NP) in the registers, and these subjects formed the sample of this study.

\section{Start and discontinuation of disability pensions}

Registers of the FCP and the SII were used to collect data on disability pensions until the end of the year 2016.

Disability pension status was first analysed based on data of the earnings-related pension system from the FCP for the years 2005-2016. Rates, reasons (i.e. if the reason for the discontinuation was the death of a person), and dates for the start and discontinuation of the disability pension were inspected. Then, we combined data from the FCP to register data from the SII, with data available for whole NFBC 1966 cohort until the end of the year 2000. For part of the sample, we also had register data of the SII for the period 2000-2016. The register of the FCP includes disability pensions of persons who have had salaried work periods/work contracts. The register of the SII includes information on disability pensions of persons who have not been working or who have not earned salary to the extent of accumulating sufficient pension in their life, including persons who have received a disability pension at a relatively young age. Data on sickness allowance were based on the register of the SII which includes all sickness allowance periods that exceed a waiting period consisting normally of 10 working days [14].

In Finland, the SII pays compensation in the form of a sickness allowance for sick leave lasting up to one year [15]. When work disability lasts longer, entitlement to a fixed-term (i.e. temporary) or permanent disability pension is considered. Please see online supplement 1 for further details.

We studied how many persons could return to the labour market after receiving fixed-term or permanent disability pension. Each subject of the sample was followed until the end of the follow-up (31.12.2016), or until death or moving abroad (information from the Population Register). Consecutive disability pension periods were combined into one, and in the case of multiple periods at different times, only the latest one was noted when analysing the discontinuation of the disability pension. TM and EJ analysed the reasons and dates for the discontinuation, and in the case of unclear information, a solution was found by consensus with JM, LAM, and MH. We wanted to focus on psychiatric reasons for disability pension. Therefore, we only present the proportions of disability pensions due to somatic reasons, but we exclude those from further analyses.

A person was considered as having returned to the labour market if disability pension was coded as ended, the person was alive at the time of discontinuation, and no new disability pension was granted. Because the register information was available until the end of the follow-up (31.12.2016), we defined disability pension as ended if it was terminated at least four months before that.

\section{Predictors}

The following predictors for return to the labour market were analysed: gender, average school grades, educational level, having children, marital status, age of illness onset, comorbid substance use disorders, proportion of time spent in psychiatric hospitalization after illness onset, age at the initiation of the latest disability pension period, and length of the latest disability pension period. Information on these was gained from national registers (Online supplement 1).

\section{Missing data and excluded subjects}

In the whole sample, 1 person with SZ, 5 with OP, and 9 with NP had deceased and did not receive disability pension, and these persons were excluded. All persons who had moved abroad (2 with SZ, 2 with OP, and 24 with NP) were excluded since we did not have information on their pension status.

Information on comorbid substance use disorder was missing from 0-5\% and the age at illness onset from 0-3\% of people in different diagnostic groups.

\section{Statistical analyses}

The background variables in different diagnostic categories were presented for those who had a disability pension for a psychiatric reason and those who did not have it by using cross-tabulation (categorical variables), median with interquartile range, and mean with standard deviation (age of illness onset). Cross-tabulation and the chi-square test were used to compare characteristics of the disability pension separately in different diagnostic groups. Logistic regression was used to examine the association of selected variables with returning to the labour market (instead of having disability pension still running). The results are presented as odds ratios (ORs) with $95 \%$ confidence intervals (CIs) and p-values. 
P-values $<0.05$ were considered as statistically significant. The statistical analyses were done using IBM SPSS Statistics, version 25 .

\section{$\underline{\text { Results }}$}

\section{Rates and reasons for disability pensions}

Before 2016, 177/229 (77\%) of persons with schizophrenia received disability pension for any reason (including also somatic disorders). Among persons with other psychosis, 102/205 (50\%), and of the non-psychotic group 277/1877 (15\%) persons had been on a disability pension.

170 (74\%) persons with SZ, 91 (44\%) with OP, and 211 (11\%) with NP had been on a disability pension for a psychiatric reason, and only they were included in further analyses (Table 2).

\section{Characteristics of the sample}

Among persons with SZ, 58\% were males. Corresponding percentages were $45 \%$ for OP and 49\% for NP. In all groups, the most common educational level was secondary education (51-52\%), basic or below in 26-29\%, and tertiary in 19$22 \%$ of the cases. The mean age of psychosis onset was 29.8 years for SZ and 36.9 years for OP, the mean age of illness onset being 34.3 years for NP (Table 2).

The main diagnosis for receiving a disability pension in the SZ group was SZ for $115(68 \%)$ persons and OP or NP for $55(32 \%)$ persons. However, the majority of these 55 persons in SZ group had a diagnosis of psychotic disorder before the disability pension. This information was based on other registers than registers of the FCP and the SII. Among these 55 persons, $29(53 \%)$ had schizophrenia and 14 (25\%) had psychosis diagnosis other than schizophrenia in some other register before the initiation of the disability pension. $12(22 \%)$ persons had psychosis diagnosis in the registers only after receiving the disability pension. It is possible that at least some of them have had onset of psychosis before the initiation of the disability pension. None of these 12 persons belonged to the group who had returned to the labour market. In the other two groups, due to the unavailability of decimals of diagnoses (F-codes in ICD-10), it was not possible to separate whether the main diagnosis for a disability pension was OP or NP.

Sixty-one percent of persons with SZ, $90 \%$ of persons with OP, and $90 \%$ of persons with NP had only one disability pension period $(\mathrm{p}<0.001$, Table 3$)$.

The type of the latest disability pension was a permanent full-time disability pension for $77 \%$ of persons with SZ, $68 \%$ of OP, and $53 \%$ of NP. A fixed-term full-time disability pension was granted for $22 \%$ of persons with SZ, $31 \%$ of OP, and $39 \%$ of NP. Few people had a partial permanent or partial fixed-term disability pension (Table 3). The difference in the type of the latest disability pension between the groups was statistically significant $(\mathrm{p}<0.001)$.

\section{Reasons for the discontinuation of the disability pension}

In SZ, the disability pensions of $15(9 \%)$ persons ended due to a return to the labour market (Table 3). Corresponding numbers for OP and NP were $17(19 \%)$ and $60(28 \%)$, respectively. The disability pensions of $19(11 \%)$ persons in the SZ group, $7(8 \%)$ in the OP group, and $12(6 \%)$ in the NP group had ended due to death. The difference in reasons for the discontinuation of the disability pension between the groups was statistically significant $(p<0.001)$.

In SZ, 2/15 had returned from a permanent full-time disability pension and 13/15 from a fixed-term full-time disability pension. Corresponding numbers were 4/17 and 13/17 in OP, and 2/60 and 51/60 in NP. In NP, 7/60 had returned from a partial permanent or fixed-term disability pension.

\section{Return to the labour market}

When analysing only those who had been granted a permanent full-time disability pension, 2/131 (2\%) persons with SZ, $4 / 62(6 \%)$ with OP, and 2/112 (2\%) persons with NP were able to return to the labour market. $13 / 37$ (35\%) persons with SZ, 13/28 (46\%) with OP, and 51/82 (62\%) persons with NP receiving a fixed-term full-time disability pension were able to return to the labour market.

\section{Predictors for return to the labour market}

In SZ, not married persons were less likely to return to the labour market than married persons (OR: 0.22 ; 95\% CI: 0.060.76 ), and those with higher average school grades (OR: 2.02; 95\% CI: 1.09-3.75) and later age of onset of psychosis (OR: 1.07 ; $95 \%$ CI: $1.02-1.11$ ) were more likely to return to the labour market (Table 4). Those having children were 
more likely to return to the labour market in OP (OR: 4.81; 95\% CI: 1.26-18.29) and NP (OR: 1.92; 95\% CI: 1.02-3.60), but not in SZ.

In all groups, the length of the latest disability pension period was significantly shorter (OR ( $95 \% \mathrm{CI}) 0.60(0.45-0.79)$ in SZ, $0.61(0.45-0.81)$ in OP, and $0.61(0.52-0.72)$ in NP) in those returning to the labour market than in those with a disability pension still running. Regarding other predictors studied, there were no statistically significant differences in any diagnostic groups.

\section{Discussion}

\section{Main findings}

Returning to the labour market in schizophrenia (9\%) is rare, but possible. Returning to the labour market was more common for other psychoses (19\%) or non-psychotic psychiatric disorders (28\%). It also tends to be more common after a fixed-term than after a permanent disability pension in all diagnostic groups.

In SZ, being married, higher onset age of psychosis, and better average school grades predicted returning to the labour market. Having children predicted returning to the labour market in OP and NP. A shorter length of the latest disability pension predicted returning to the labour market in all groups.

\section{Comparison to previous studies}

Our number of persons with SZ returning to the labour market is in line with the employment rates of 10-20\% [3] and with the unemployment rates of $89-94 \%$ found in previous studies [4]. In addition, in a recent Finnish study, only $10.5 \%$ of persons with a psychiatric disability pension returned to work within the five years of follow-up [20].

Among psychiatric disorders, psychotic diagnoses have the poorest occupational outcomes after long-term work disability $[9,10]$. In parallel to few previous studies on RTW, our study shows even lower numbers of returnees to working life (in our study SZ 9\% and OP 19\% vs. in Joensuu et al. [9] 40-\% and Virtanen et al. [10] 46\% of persons with schizophrenia, schizotypal, or delusional disorder). This difference can be explained by the facts that we focused on more severe stages of work disability, we had a notably longer follow-up, and different settings since the register of SII includes subjects with no lifetime attachment to working life because of disabilities occurring at a younger age. Permanent disability pensions are granted based on a much lower probability of regaining working ability compared to fixed-term disability pensions and long-term sick leaves. Virtanen et al. [10] defined work disability broadly as long-term sick leave ( $\geq 90$ days) or the receipt of disability pension without separating permanent and fixed-term ones. Following their recommendation, we were able to study permanent and temporary disability pensions separately.

Our sample differs from many other studies because we used the most severe lifetime diagnoses detected from several registers. Whereas previous studies have analysed returning to the labour market of persons who have received disability pension due to diagnosis of schizophrenia or psychosis (regardless of their previous and forthcoming diagnoses in treatment settings), we analysed returning to the labour market among those with lifetime schizophrenia or other psychosis. Hence, we have explored a very good functioning outcome during life course among people with psychotic disorders.

Returning from a disability pension in schizophrenia is not common. This is reflected in the high proportion of permanent full-time disability pensions (77\%) granted for those with SZ, indicating a severe illness. On the other hand, this may reflect the views of mental health care workers thinking that it is not possible to recover occupationally from schizophrenia [21]. However, many persons with schizophrenia spectrum disorders can do some work and vocational rehabilitation should be offered for those who wish to work [22]. Implementing individual placement and support also seems to increase the employment rates for people with mental health problems [23]. One reason for the importance of vocational rehabilitation is that employment is beneficial for mental health [24].

Our results give us hope by showing possibilities for returning to the labour market even after long-term disability pensions. Some studies have reported better longitudinal employment outcomes for patients receiving early intervention services, but the association is not clear [25]. Vocational or educational rehabilitation seems to improve involvement in school or work in early-phase psychosis [26]. Since in our study returning to the labour market was possible also in later stages of illness, this kind of rehabilitation services should be offered not only to all patients in the early phase but also later during the course of illness. 
In OP or NP, the rates of permanent full-time disability pensions (68\% in OP and 53\% in NP) were somewhat lower than in schizophrenia. That may partly explain the higher proportions of people who can return to the labour market compared to SZ. The total number of persons with schizophrenia on a disability pension at some point (77\%) was also remarkably larger compared to OP $(50 \%)$ or NP $(15 \%)$.

Schizophrenia patients are at high risk of being outside the labour market [2]. The societal costs of schizophrenia, including lost productivity due to being outside the labour force, are worth noting [1]. Also, in terms of treatment, supporting the ability to work or study is an important goal in schizophrenia because it can further promote functional, clinical, and social outcomes [27].

In an extensive review, higher cognitive functioning was identified as a significant predictor of good vocational outcome in schizophrenia [28]. In our study, higher school marks at the age of 16 years predicted a return to the labour market. Better school performance has also previously been found as a predictor of not being on a disability pension in schizophrenia in NFBC1966 [29]. Higher school marks may be a proxy of cognitive functioning and reserve, and in this sense, our results are in line with previous studies [28]. Other predictors of good vocational outcome in the study by Tsang et al. [28] included a lower level of negative symptoms, a higher level of education, social support and skills, a previous history of successful employment, younger age, and use of rehabilitation services. According to large meta-analyses, the association between onset age and outcomes in schizophrenia is not clear, though some studies report a significant relationship between those [28, 30]. Later illness onset has been associated with many other good outcomes in schizophrenia [30].

Tsang et al. [28] found that being married or cohabiting predicts better vocational outcome, and our results are in line with this. Being single has also been associated with worse occupational outcomes in earlier follow-ups in NFBC1966 [5]. Having children predicted returning to the labour market in OP and NP but not in SZ. Schizophrenia patients without children have been found to have a more severe and prolonged course of illness than those with children [31], while the association between having children and outcome in other psychoses is less known. We found that a shorter length of the latest disability pension predicts returning to the labour market in SZ, OP, and NP. Having long-term sick leave due to mental illness has been reported increasing the risks of both disability pension and unemployment [32].

Our results show that factors that have previously been reported as having an association with better outcomes in schizophrenia are also predictors for a return to the labour market. These findings can be utilised when planning treatment and rehabilitation for persons with schizophrenia. For example, effective planning and implementation of occupational rehabilitation could be offered especially for those who have markers of better possibilities to return to the labour market.

\section{Strengths and limitations}

NFBC1966 offered us a unique possibility to examine the return to the labour market in psychoses and non-psychotic disorders with full register-based data coverage of an unselected, general population sample covering all branches of economy and occupations over a time period of 50 years.

Due to the long follow-up, period effects should be noted. Especially after the 1990s, both funding possibilities and views on occupational rehabilitation changed. Possibilities for rehabilitation aiming to return to work increased and rehabilitation became more working life oriented. On the other hand, working life has become more demanding psychologically, cognitively, and socially, hampering employment opportunities especially for those with schizophrenia. In addition, changes in grounds for granting disability pensions may have differed during decades. The use of three diagnostic systems and differences in diagnostic practices over the decades, may have influenced not only variation in the prevalence of different diagnoses but also differences in the granting of disability pensions.

An important strength of the study was high-quality register data. In Finland, the universal, both earnings- and citizenshipbased and comprehensively registered disability pension system gave us an opportunity to examine different phases of pension periods very precisely. Unlike in previous studies, our data also covered persons who had not been able to enter working life due to early illness onset or other reasons. This is an important aspect regarding psychoses which are among the main reasons for disability in early working age. Due to this, our results fully describe the psychiatric disability-related outcomes in all persons with schizophrenia and other mental disorders in this population. The small number of cases, however, especially when analysing the predictors, limits the statistical power. An important limitation in our study was the potential missing of non-psychotic mental disorders. Our registers probably include the majority of persons with psychosis [5], but those with NP treated solely in occupational health or private sector and those without any treatment are not included in the registers we used, and may have been missed. Also, the national data collection of the visits to specialized outpatient care started in 1998 when the cohort members were over 30 years old. Thus, the prevalence 
observed for non-psychotic mental disorders (15.6\%) may be underestimated. Our prevalence observed for any mental disorder (19.2\%) is within the range of prevalence estimates (12.2-48.6\%) found in a cross-national study [33], but lower than lifetime prevalence in the Dunedin Study (85.8\%) [34]. It is possible that some persons with NP may have had psychotic symptoms or a diagnosis, but they have not ended up in the registers. However, we did our best to classify the subjects by using several national registers.

One problem among studies focusing on disability- and employment-related outcomes is in defining and measuring the outcome. There are no standard definitions describing a good occupational outcome or being employed in schizophrenia research [3]. There is also a difference in returning to competitive work compared to returning to the labour market, which we could unfortunately not assess with the data available for this study. Nevertheless, we studied the ending of disability pension due to psychiatric reasons and returning to the labour market with an unambiguous measure, showing clear differences between the diagnostic groups studied.

\section{Conclusion}

Although schizophrenia is associated with long-term work disability, it is possible to return to the labour market after periods on a disability pension. Among other psychoses and non-psychotic disorders, returning to the labour market is somewhat more common than in schizophrenia. To improve the occupational outcome for people with psychoses, in the future, it is important to study factors associated with a return to the labour market and work in large samples with long follow-up.

\section{$\underline{\text { Declarations }}$}

\section{Funding}

Oulu University Hospital funding (basic government funding for hospitals).

\section{Conflict of interest}

The authors declare that they have no conflict of interest.

\section{Ethical statement}

The NFBC1966 study has been approved by the Ethics Committee of the Northern Ostrobothnia Hospital District and relevant keepers of the registers. The study has been performed in accordance with the ethical standards laid down in the 1964 Declaration of Helsinki and its later amendments. According to Finnish legislation, individual consents are not needed for solely register-based studies.

\section{Availability of data and material}

The data is under gated access. Data is available from the NFBC project center (NFBCprojectcenter@oulu.fi) for researchers who meet the criteria for accessing confidential data (www.oulu.fi/nfbc).

\section{Code availability}

Not applicable.

\section{$\underline{\text { References }}$}

1. Evensen S, Wisløff T, Lystad JU, Bull H, Ueland T, Falkum E (2016) Prevalence, employment rate, and cost of schizophrenia in a high-income welfare society: a population-based study using comprehensive health and welfare registers. Schizophrenia Bull 42(2):476-483

2. Hakulinen C, McGrath JJ, Timmerman A, Skipper N, Mortensen PB, Pedersen CB, Agerbo E (2019) The association between early-onset schizophrenia with employment, income, education, and cohabitation status: nationwide study with 35 years of follow-up. Soc Psychiatry Psychiatr Epidemiol 54(11):1343-1351

3. Marwaha S, Johnson S. (2004) Schizophrenia and employment - a review. Soc Psychiatry Psychiatr Epidemiol 39(5): 337-349

4. Hakulinen C, Elovainio M, Arffman M, Lumme S, Pirkola S, Keskimäki I, Manderbacka K, Böckerman P (2019) Mental disorders and long-term labour market outcomes: nationwide cohort study of 2055720 individuals. Acta Psychiatr Scand 140(4):371-381 
5. Miettunen J, Lauronen E, Veijola J, Koponen H, Saarento O, Taanila A, Isohanni M (2007) Socio-demographic and clinical predictors of occupational status in schizophrenic psychoses--follow-up within the Northern Finland 1966 Birth Cohort. Psychiatry Res 150(3):217-225

6. Karpov B, Joffe G, Aaltonen K, Suvisaari J, Baryshnikov I, Näätänen P, Koivisto M, Melartin T, Oksanen J, Suominen K, Heikkinen M, Isometsä E (2017) Level of functioning, perceived work ability, and work status among psychiatric patients with major mental disorders. Eur Psychiatry 44:83-89

7. Jääskeläinen E, Juola P, Hirvonen N, McGrath JJ, Saha S, Isohanni M, Veijola J, Miettunen J (2013) A systematic review and meta-analysis of recovery in schizophrenia. Schizophr Bull 39(6):1296-1306

8. Desiron HAM, de Rijk A, Van Hoof E, Donceel P (2011) Occupational therapy and return to work: a systematic literature review. BMC Public Health 11(1):615

9. Joensuu M, Mattila-Holappa P, Ahola K, Kivimäki M, Tuisku K, Koskinen A, Vahtera J, Virtanen M (2019) Predictors of employment in young adults with psychiatric work disability. Early Interv Psychiatry 13(5):1083-1089

10. Virtanen M, Kawachi I, Oksanen T, Salo P, Tuisku K, Pulkki-Råback L, Pentti J, Elovainio M, Vahtera J, Kivimäki M (2011) Socio-economic differences in long-term psychiatric work disability: prospective cohort study of onset, recovery, and recurrence. Occup Environ Med 68(11):791-798

11. Rantakallio P (1988) The longitudinal study of the northern Finland birth cohort of 1966. Paediatr Perinat Epidemiol 2(1):59-88

12. Filatova S, Marttila R, Koivumaa-Honkanen H, Nordström T, Veijola J, Mäki P, Khandaker GM, Isohanni M, Jääskeläinen E, Moilanen K, Miettunen J (2017) A comparison of the cumulative incidence and early risk factors for psychotic disorder in young adults in the Northern Finland Birth Cohorts 1966 and 1986. Epidemiol Psychiatr Sci 26(3):314-324

13. Nietola M, Heiskala A, Nordström T, Miettunen J, Korkeila J, Jääskeläinen E (2018) Clinical characteristics and outcomes of psychotic depression in the Northern Finland Birth Cohort 1966. Eur Psychiatry 53:23-30

14. The Social Insurance Institution of Finland (2014) Statistical Yearbook of the Social Insurance Institution, 2013. Vammalan kirjapaino, Sastamala

15. Finnish Centre for Pensions (2020) Disability pension, Finland. https://www.etk.fi/en/the-pension-system/pensionsecurity/earnings-related-pension-benefits/disability-pension/. Accessed 21 April 2020

16. Keskinen E, Marttila R, Koivumaa-Honkanen H, Moilanen K, Keinänen-Kiukaanniemi S, Timonen M, Isohanni M, McGrath J, Miettunen J, Jääskeläinen E (2018) Search for protective factors for psychosis - a population-based sample with special interest in unaffected individuals with parental psychosis. Early Interv Psychiatry 12(5):869-878

17. Isohanni I, Järvelin MR, Jones P, Jokelainen J, Isohanni M (1999) Can excellent school performance be a precursor of schizophrenia? A 28-year follow-up in the Northern Finland 1966 birth cohort. Acta Psychiatr Scand 100(1):1726

18. International Standard Classification of Education (2011) Eurostat ISCED. https://ec.europa.eu/ eurostat/statisticsexplained/index.php/International_Standard_Classification_of_Education_(ISCED). Accessed 21 April 2020

19. Haapea M, Miettunen J, Veijola J, Lauronen E, Tanskanen P, Isohanni M (2007) Non-participation may bias the results of a psychiatric survey: an analysis from the survey including magnetic resonance imaging within the Northern Finland 1966 Birth Cohort. Soc Psychiatry Psychiatr Epidemiol 42(5):403-409

20. Pirkola S, Nevalainen J, Laaksonen M, Fröjd S, Nurmela K, Näppilä T, Tuulio-Henriksson A, Autio R, Blomgren J (2019) The importance of clinical and labour market histories in psychiatric disability retirement: analysis of the comprehensive Finnish national-level RETIRE data. Soc Psychiatry Psychiatr Epidemiol. Published online 5 December 2019

21. Marwaha S, Balachandra S, Johnson S (2009) Clinicians' attitudes to the employment of people with psychosis. Soc Psychiatry Psychiatr Epidemiol 44(5):349-360

22. Falkum E, Klungsøyr O, Lystad JU, Bull HC, Evensen S, Martinsen EW, Friis S, Ueland T (2017) Vocational rehabilitation for adults with psychotic disorders in a Scandinavian welfare society. BMC Psychiatry 17(1):24

23. Rinaldi M, Montibeller T, Perkins R (2011) Increasing the employment rate for people with longer-term mental health problems. Psychiatrist 35(9):339-343

24. van der Noordt M, IJzelenberg H, Droomers M, Proper KI (2014) Health effects of employment: a systematic review of prospective studies. Occup Environ Med 71(10):730-736

25. Chan SKW, Chan HYV, Devlin J, Bastiampillai T, Mohan T, Hui CLM, Chang WC, Lee EHM, Chen EYH (2019) A systematic review of long-term outcomes of patients with psychosis who received early intervention services. Int Rev Psychiatry 31(5-6):425-440

26. Correll CU, Galling B, Pawar A, Krivko A, Bonetto C, Ruggeri M, Craig TJ, Nordentoft M, Srihari VH, Guloksuz S, Hui CLM, Chen EYH, Valencia M, Juarez F, Robinson DG, Schooler NR, Brunette MF, Mueser KT, Rosenheck RA, Marcy P, Addington J, Estroff SE, Robinson J, Penn D, Severe JB, Kane JM (2018) Comparison of Early 
Intervention Services vs Treatment as Usual for Early-Phase Psychosis: A Systematic Review, Meta-analysis, and Meta-regression. JAMA Psychiatry 75(6):555-565

27. Tandberg M, Ueland T, Andreassen OA, Sundet K, Melle I (2012) Factors associated with occupational and academic status in patients with first-episode psychosis with a particular focus on neurocognition. Soc Psychiatry Psychiatr Epidemiol 47(11):1763-1773

28. Tsang HWH, Leung AY, Chung RCK, Bell M, Cheung W (2010) Review on vocational predictors: a systematic review of predictors of vocational outcomes among individuals with schizophrenia: an update since 1998. Aust N Z J Psychiatry 44(6):495-504

29. Lauronen E, Miettunen J, Veijola J, Karhu M, Jones PB, Isohanni M (2007) Outcome and its predictors in schizophrenia within the Northern Finland 1966 Birth Cohort. Eur Psychiatry 22(2):129-136

30. Immonen J, Jääskeläinen E, Korpela H, Miettunen J. (2017) Age at onset and the outcomes of schizophrenia: A systematic review and meta-analysis. Early Interv Psychiatry 11(6):453-460

31. Ritsner M, Sherina O, Ginath Y (1992) Genetic epidemiological study of schizophrenia: reproduction behaviour. Acta Psychiatr Scand 85(6):423-429

32. Hultin H, Lindholm C, Möller J (2012) Is there an association between long-term sick leave and disability pension and unemployment beyond the effect of health status? - a cohort study. PLoS ONE 7(4):e35614

33. Andrade L, Caraveo-Anduaga J, Berglund P, Bijl R, Kessler R, Demler O et al (2000) Cross-national comparisons of the prevalences and correlates of mental disorders. Bull World Health Organ 78(4):413-426

34. Caspi A, Houts RM, Ambler A, Danese A, Elliott ML, Hariri A, Harrington H, Hogan S, Poulton R, Ramrakha S, Rasmussen LJH, Reuben A, Richmond-Rakerd L, Sugden K, Wertz J, Williams BS, Moffitt TE (2020) Longitudinal Assessment of Mental Health Disorders and Comorbidities Across 4 Decades Among Participants in the Dunedin Birth Cohort Study. JAMA Netw Open 3(4):e203221 
Table 1. Diagnostic categories based on ICD 8-10 used in the current study.

\begin{tabular}{|c|c|c|c|}
\hline & ICD-8 (1968-86) & ICD-9 (1987-95) & ICD-10 (1996-) \\
\hline Schizophrenia (SZ) & $2950-2959,297$ & $2950-2959,297$ & F20, F22, F24, F25 \\
\hline Other Psychosis (OP) & 2960-2969, 2980-2983, 2988, 2989, 299 & $\begin{array}{l}\text { 2961E, 2962E, 2963E, 2964E, 2967, } \\
\text { 2988, } 2989\end{array}$ & $\begin{array}{l}\text { F23, F28, F29, F302, F312, F315, F323, } \\
\text { F333 }\end{array}$ \\
\hline Non-psychotic psychiatric disorder (NP) & $\begin{array}{l}295-308,310-315,7092 \text {, (excluding } \\
\text { those with diagnosis of SZ or OP } \\
\text { described above) }\end{array}$ & $\begin{array}{l}295-309,311-319 \text {, (excluding those with } \\
\text { diagnosis of SZ or OP described above) }\end{array}$ & $\begin{array}{l}\text { F101, F102, F111, F112, F121, F122, } \\
\text { F131, F132, F141, F142, F151, F152, } \\
\text { F161, F162, F171, F172, F181, F182, } \\
\text { F191, F192, and F20-F99, (excluding } \\
\text { those with diagnosis of SZ or OP } \\
\text { described above) }\end{array}$ \\
\hline
\end{tabular}


Table 2. Characteristics of the sample

\begin{tabular}{|c|c|c|c|c|c|c|c|c|c|}
\hline \multirow[t]{2}{*}{ Variable } & \multicolumn{3}{|c|}{ Schizophrenia } & \multicolumn{3}{|c|}{ Other psychosis } & \multicolumn{3}{|c|}{ Non-psychotic psychiatric disorder } \\
\hline & $\begin{array}{c}\text { Disability } \\
\text { pension for } \\
\text { a psychiatric } \\
\text { reason } \\
(\mathrm{n}=170)\end{array}$ & $\begin{array}{c}\text { No } \\
\text { disability } \\
\text { pension } \\
(\mathrm{n}=53)\end{array}$ & $\begin{array}{c}\text { Total } \\
(\mathrm{n}=223)\end{array}$ & $\begin{array}{l}\text { Disability } \\
\text { pension for } \\
\text { a psychiatric } \\
\text { reason } \\
(\mathrm{n}=91)\end{array}$ & $\begin{array}{c}\text { No } \\
\text { disability } \\
\text { pension } \\
(\mathrm{n}=109)\end{array}$ & $\begin{array}{c}\text { Total } \\
(\mathrm{n}=200)\end{array}$ & $\begin{array}{c}\text { Disability } \\
\text { pension for } \\
\text { a psychiatric } \\
\text { reason } \\
(\mathrm{n}=211)\end{array}$ & $\begin{array}{c}\text { No } \\
\text { disability } \\
\text { pension } \\
(\mathrm{n}=1604)\end{array}$ & $\begin{array}{c}\text { Total } \\
(\mathrm{n}=1815)\end{array}$ \\
\hline \multicolumn{10}{|l|}{ Gender, n (\%) } \\
\hline Male & $99(58.2)$ & $31(58.5)$ & $130(58.3)$ & $41(45.1)$ & $59(54.1)$ & $100(50.0)$ & $104(49.3)$ & $761(47.4)$ & $865(47.7)$ \\
\hline Female & $71(41.8)$ & $22(41.5)$ & $93(41.7)$ & $50(54.9)$ & $50(45.9)$ & $100(50.0)$ & $107(50.7)$ & $843(52.6)$ & $950(52.3)$ \\
\hline \multicolumn{10}{|l|}{ Educational levela $^{\mathrm{a}}$, n (\%) } \\
\hline Basic or below & $49(28.8)$ & $5(9.4)$ & $54(24.2)$ & $24(26.4)$ & $17(15.6)$ & $41(20.5)$ & $57(27.0)$ & $226(14.1)$ & $283(15.6)$ \\
\hline Secondary & $89(52.4)$ & $25(47.2)$ & $114(51.1)$ & 47 (51.6) & $59(54.1)$ & $106(53.0)$ & $107(50.7)$ & $807(50.3)$ & $914(50.4)$ \\
\hline Tertiary & $32(18.8)$ & $23(43.4)$ & $55(24.7)$ & $20(22.0)$ & $33(30.3)$ & $53(26.5)$ & $47(22.3)$ & $571(35.6)$ & $618(34.0)$ \\
\hline \multicolumn{10}{|l|}{ Having children $^{b}, \mathbf{n}(\%)$} \\
\hline No & $123(72.4)$ & $26(49.1)$ & $149(66.8)$ & $38(41.8)$ & $36(33.0)$ & $74(37.0)$ & $85(40.3)$ & $331(20.6)$ & $416(22.9)$ \\
\hline Yes & $47(27.6)$ & $27(50.9)$ & $74(33.2)$ & $53(58.2)$ & $73(67.0)$ & $126(63.0)$ & $126(59.7)$ & $1273(79.4)$ & $1399(77.1)$ \\
\hline \multicolumn{10}{|l|}{ Marital status $^{\mathbf{b}}, \mathbf{n}(\%)$} \\
\hline Not married & $125(73.5)$ & $35(66.0)$ & $160(71.7)$ & $38(41.8)$ & $46(42.2)$ & $84(42.0)$ & $90(42.7)$ & $469(29.2)$ & $559(30.8)$ \\
\hline Married & $20(11.8)$ & $10(18.9)$ & $30(13.5)$ & $22(24.2)$ & $27(24.8)$ & $49(24.5)$ & $62(29.4)$ & $729(45.4)$ & $791(43.6)$ \\
\hline Divorced or widowed & $25(14.7)$ & $8(15.1)$ & $33(14.8)$ & $31(34.1)$ & $36(33.0)$ & $67(33.5)$ & $59(28.0)$ & $406(25.3)$ & $465(25.6)$ \\
\hline $\begin{array}{l}\text { Age of illness onset, psychosis (years), } \\
\text { Mean (SD) }\end{array}$ & $29.8(8.6)$ & $32.4(8.1)$ & $30.4(8.5)$ & $36.9(9.4)$ & $36.4(9.1)$ & $36.7(9.2)$ & & & \\
\hline Md (IQR) & $\begin{array}{c}29.3 \\
(23.1-35.5)\end{array}$ & $\begin{array}{c}31.5 \\
(26.5-38.0)\end{array}$ & $\begin{array}{c}30.3 \\
(24.1-36.6)\end{array}$ & $\begin{array}{c}38.0 \\
(33.6-44.3)\end{array}$ & $\begin{array}{c}38.2 \\
(28.5-44.2)\end{array}$ & $\begin{array}{c}38.1 \\
(30.7-44.3)\end{array}$ & & & \\
\hline $\begin{array}{l}\text { Age of illness onset, non-psychotic } \\
\text { psychiatric disorder (years), Mean } \\
\text { (SD) }\end{array}$ & & & & & & & $34.3(10.3)$ & $38.2(11.5)$ & $37.7(11.4)$ \\
\hline Md (IQR) & & & & & & & $\begin{array}{c}36.5 \\
(28.4-42.1)\end{array}$ & $\begin{array}{c}42.1 \\
(32.5-47.1)\end{array}$ & $\begin{array}{c}41.3 \\
(32.1-46.7)\end{array}$ \\
\hline
\end{tabular}

${ }^{\mathrm{a} U n t i l} 2015$

${ }^{b}$ Until June 2016

Abbreviations: $\mathrm{SD}=$ standard deviation, $\mathrm{Md}=$ median, $\mathrm{IQR}=$ interquartile range 
Table 3. Characteristics of the disability pension

\begin{tabular}{|c|c|c|c|c|c|c|}
\hline & \multicolumn{2}{|c|}{$\begin{array}{c}\begin{array}{c}\text { Schizophrenia } \\
(\mathrm{n}=170)\end{array} \\
\end{array}$} & \multicolumn{2}{|c|}{$\begin{array}{c}\text { Other psychosis } \\
(\mathrm{n}=91)\end{array}$} & \multicolumn{2}{|c|}{$\begin{array}{l}\text { Non-psychotic psychiatric disorder } \\
(\mathrm{n}=211)\end{array}$} \\
\hline & $\mathrm{n}$ & $\%$ & $\mathrm{n}$ & $\%$ & $\mathrm{n}$ & $\%$ \\
\hline \multicolumn{7}{|l|}{ Number of disability pension periods, $\mathbf{n} / \%$} \\
\hline One & 103 & 60.6 & 82 & 90.1 & 189 & 89.6 \\
\hline Two or more & 67 & 39.4 & 9 & 9.9 & 22 & 10.4 \\
\hline \multicolumn{7}{|l|}{ Type of the disability pension received, $\mathbf{n} / \%$} \\
\hline Permanent full-time disability pension & 131 & 77.1 & 62 & 68.1 & 112 & 53.1 \\
\hline Fixed-term full-time disability pension & 37 & 21.8 & 28 & 30.8 & 82 & 38.9 \\
\hline Partial permanent or fixed-term disability pension & 2 & 1.2 & 1 & 1.1 & 17 & 8.1 \\
\hline \multicolumn{7}{|l|}{ Disability pension status at the end of the follow-up, $n / \%$} \\
\hline Disability pension ended due to death & 19 & 11.2 & 7 & 7.7 & 12 & 5.7 \\
\hline Disability pension still running & 136 & 80.0 & 67 & 73.6 & 139 & 65.9 \\
\hline $\begin{array}{l}\text { Disability pension ended and alive (i.e. return to labour } \\
\text { market) }\end{array}$ & 15 & 8.8 & 17 & 18.7 & 60 & 28.4 \\
\hline
\end{tabular}


Table 4. Predictors for return to labour market by the age of 50 years (vs. disability pension still running)

\begin{tabular}{|c|c|c|c|c|c|c|c|c|c|c|c|c|}
\hline \multirow[t]{2}{*}{ Variable } & \multicolumn{4}{|c|}{ Schizophrenia } & \multicolumn{4}{|c|}{ Other psychosis } & \multicolumn{3}{|c|}{ Non-psychotic psychiatric disorder } & \multirow[b]{2}{*}{ p-value } \\
\hline & $\begin{array}{l}\text { Return to } \\
\text { labour } \\
\text { market } \\
(\mathrm{n}=15)\end{array}$ & $\begin{array}{c}\text { Disability } \\
\text { pension } \\
\text { still } \\
\text { running } \\
(\mathrm{n}=136) \\
\end{array}$ & OR $(95 \% \mathrm{CI})$ & p-value & $\begin{array}{l}\text { Return to } \\
\text { labour } \\
\text { market } \\
(\mathrm{n}=17)\end{array}$ & $\begin{array}{c}\text { Disability } \\
\text { pension still } \\
\text { running } \\
(\mathrm{n}=67)\end{array}$ & OR $(95 \% \mathrm{CI})$ & p-value & $\begin{array}{l}\text { Return to } \\
\text { labour } \\
\text { market } \\
(\mathrm{n}=60)\end{array}$ & $\begin{array}{c}\text { Disability } \\
\text { pension still } \\
\text { running } \\
(\mathrm{n}=139)\end{array}$ & OR $(95 \% \mathrm{CI})$ & \\
\hline Gender, n (\%) & & & & 0.680 & & & & 0.627 & & & & 0.939 \\
\hline Male $^{1}$ & $9(60.0)$ & $74(54.4)$ & 1 & & $6(35.3)$ & $28(41.8)$ & 1 & & $29(48.3)$ & $68(48.9)$ & 1 & \\
\hline Female & $6(40.0)$ & $62(45.6)$ & $0.80(0.27-2.36)$ & & $11(64.7)$ & $39(58.2)$ & $1.32(0.44-3.98)$ & & $31(51.7)$ & $71(51.1)$ & $1.02(0.56-1.88)$ & \\
\hline $\begin{array}{l}\text { Average school grades at the age } \\
\text { of } 16 \text { years, Mean (SD) }\end{array}$ & $7.8(0.9)$ & $7.3(0.9)$ & $2.02(1.09-3.75)$ & 0.026 & $7.6(1.0)$ & $7.4(1.0)$ & $1.19(0.68-2.07)$ & 0.552 & $7.2(0.9)$ & $7.2(0.9)$ & $1.06(0.74-1.52)$ & 0.740 \\
\hline Educational level $\mathrm{a}^{\mathrm{a}}, \mathrm{n}(\%)$ & & & & 0.754 & & & & 0.297 & & & & 0.227 \\
\hline Basic or below 1 & $4(26.7)$ & $35(25.7)$ & 1 & & $2(11.8)$ & $21(31.3)$ & 1 & & $12(20.0)$ & $40(28.8)$ & 1 & \\
\hline Secondary & $7(46.7)$ & $75(55.1)$ & $0.82(0.22-2.97)$ & & $10(58.8)$ & $32(47.8)$ & $3.28(0.65-16.50)$ & & $30(50.0)$ & $71(51.1)$ & $1.41(0.65-3.05)$ & \\
\hline Tertiary & $4(26.7)$ & $26(19.1)$ & $1.35(0.31-5.89)$ & & $5(29.4)$ & $14(20.9)$ & $3.75(0.64-22.10)$ & & $18(30.0)$ & $28(20.1)$ & $2.14(0.89-5.14)$ & \\
\hline Having children ${ }^{\mathrm{b}}, \mathbf{n}(\%)$ & & & & 0.218 & & & & 0.021 & & & & 0.044 \\
\hline $\mathrm{No}^{1}$ & $9(60.0)$ & $102(75.0)$ & 1 & & $3(17.6)$ & $34(50.7)$ & 1 & & $20(33.3)$ & $68(48.9)$ & 1 & \\
\hline Yes & $6(40.0)$ & $34(25.0)$ & $2.00(0.66-6.03)$ & & $14(82.4)$ & $33(49.3)$ & $4.81(1.26-18.29)$ & & $40(66.7)$ & $71(51.1)$ & $1.92(1.02-3.60)$ & \\
\hline Marital status ${ }^{\mathrm{b}}, \mathbf{n}(\%)$ & & & & 0.049 & & & & 0.688 & & & & 0.082 \\
\hline Married $^{1}$ & $5(33.3)$ & $14(10.3)$ & 1 & & $6(35.3)$ & $17(25.4)$ & 1 & & $24(40.0)$ & $42(30.2)$ & 1 & \\
\hline Not married & $8(53.3)$ & $111(81.6)$ & $0.22(0.06-0.76)$ & & $8(47.1)$ & $34(50.7)$ & $0.67(0.20-2.23)$ & & $22(36.7)$ & $75(54.0)$ & $0.51(0.26-1.02)$ & \\
\hline Divorced or widowed & $2(13.3)$ & $11(8.1)$ & $0.55(0.09-3.35)$ & & $3(17.6)$ & $16(23.9)$ & $0.53(0.11-2.49)$ & & $14(23.3)$ & $22(15.8)$ & $1.11(0.48-2.57)$ & \\
\hline $\begin{array}{l}\text { Comorbid substance use } \\
\text { disordera } \mathbf{n}(\%)\end{array}$ & & & & 0.113 & & & & 0.440 & & & & 0.150 \\
\hline $\mathrm{No}^{1}$ & $10(66.7)$ & $113(83.7)$ & 1 & & $13(76.5)$ & $44(66.7)$ & 1 & & 41 (71.9) & $109(81.3)$ & 1 & \\
\hline Yes & $5(33.3)$ & $22(16.3)$ & $2.57(0.80-8.25)$ & & $4(23.5)$ & $22(33.3)$ & $0.62(0.18-2.11)$ & & $16(28.1)$ & $25(18.7)$ & $1.70(0.83-3.51)$ & \\
\hline $\begin{array}{l}\text { Age of illness onset, psychosis, Md } \\
\text { (IOR) }\end{array}$ & $\begin{array}{l}33.3(30.4- \\
45.7)\end{array}$ & $\begin{array}{l}29.1(23.5- \\
35.7)\end{array}$ & $1.07(1.02-1.11)$ & 0.005 & $\begin{array}{l}40.7(34.7- \\
44.1)\end{array}$ & $\begin{array}{l}38.4(33.0- \\
44.5\end{array}$ & $1.03(0.97-1.10)$ & 0.351 & & & & \\
\hline $\begin{array}{l}\text { Age of illness onset, non-psychotic } \\
\text { psychiatric disorder, Md (IQR) }\end{array}$ & & & & & & & & & $\begin{array}{l}35.4(28.6- \\
41.2)\end{array}$ & $\begin{array}{l}37.9(29.4- \\
\quad 43.0)\end{array}$ & $0.99(0.97-1.02)$ & 0.688 \\
\hline $\begin{array}{l}\text { Age at the initiation of the latest } \\
\text { disability pension period, Md } \\
\text { (IQR) }\end{array}$ & $\begin{array}{l}35.6(28.0- \\
41.6)\end{array}$ & $\begin{array}{l}32.2(25.5- \\
40.1)\end{array}$ & $1.04(0.98-1.11)$ & 0.199 & $\begin{array}{l}38.7(34.5- \\
44.9)\end{array}$ & $\begin{array}{l}39.0(26.7- \\
43.0)\end{array}$ & $1.05(0.98-1.11)$ & 0.150 & $\begin{array}{l}40.8(36.3- \\
44.8)\end{array}$ & $\begin{array}{l}42.3(35.2- \\
45.3)\end{array}$ & $1.01(0.97-1.04)$ & 0.708 \\
\hline $\begin{array}{l}\text { Length of the latest disability } \\
\text { pension period (years), Md (IQR) }\end{array}$ & $\begin{array}{l}2.3(1.1- \\
6.7)\end{array}$ & $\begin{array}{l}17.6(10.2- \\
25.0)\end{array}$ & $0.60(0.45-0.79)$ & $<0.001$ & $\begin{array}{l}1.8(0.7- \\
6.8)\end{array}$ & $\begin{array}{l}11.2(7.1- \\
23.8)\end{array}$ & $0.61(0.45-0.81)$ & $<0.001$ & $\begin{array}{l}1.7(1.0- \\
3.1)\end{array}$ & $8.2(5.3-15.3)$ & $0.61(0.52-0.72)$ & $<0.001$ \\
\hline $\begin{array}{l}\text { Proportion of time (\%) spent in } \\
\text { psychiatric hospitalization after } \\
\text { illness onset }{ }^{b}, \mathbf{M d}(\mathbf{I Q R})\end{array}$ & $\begin{array}{l}8.2(12.9- \\
35.1)\end{array}$ & $\begin{array}{l}7.7(2.3- \\
18.0)\end{array}$ & $2.85(0.64-12.65)$ & 0.168 & $\begin{array}{l}2.2(0.2- \\
9.2)\end{array}$ & $3.8(0.2-8.4)$ & $4.62(0.19-114.0)$ & 0.350 & $\begin{array}{l}0.0(0.0- \\
1.9)\end{array}$ & $0.0(0.0-1.4)$ & $10.56(0.44-254.8)$ & 0.147 \\
\hline
\end{tabular}

\section{illness onset, $\mathrm{Md}(\mathrm{IQR})$}

${ }^{a}$ Until 2015

${ }^{\mathrm{b}}$ Status at the initiation of the latest disability pension period

Abbreviations: $\mathrm{OR}=$ odds ratio, $\mathrm{CI}=$ confidence interval, $\mathrm{Md}=$ median, $\mathrm{IQR}=$ interquartile range, $\mathrm{SD}=$ standard deviation 


\section{Online supplement 1}

\section{Methods}

\section{Sample}

In this study, the focus was on individuals with schizophrenia (SZ) and other psychoses (OP), and for comparison purposes, we extracted data concerning those with non-psychotic mental disorder (NP). When setting the diagnosis for the subject, we used a hierarchical system, in which the life-time diagnosis for each subject was the one that had the highest position in the hierarchy. The hierarchical order of diagnoses was from the most severe to less severe the following: schizophrenia, other psychosis (including e.g. psychotic affective disorders and psychosis not otherwise specified), non-psychotic disorders. For example, subjects with a schizophrenia diagnosis might have had some other psychotic or non-psychotic diagnoses, but their life-time diagnosis was interpreted to be SZ. Subjects with non-psychotic disorder should not have had a diagnosis of psychosis in any of the registers, because such a diagnosis would have moved them to the respective psychosis diagnostic group.

\section{Start and discontinuation of disability pensions}

In Finland, the Social Insurance Institution of Finland (SII) pays compensation in the form of a sickness allowance for sick leave lasting up to one year [1]. When work disability lasts longer, entitlement to a fixed-term (i.e. temporary) or permanent disability pension is considered. A fixed-term disability pension is paid for a fixed period, and it can be granted to persons who have lost their ability to work temporarily but whose illness or handicap is expected to improve through treatment and rehabilitation. A permanent disability pension is granted directly if return to work (RTW) is unlikely, or after the fixed-term disability pension when treatment and rehabilitation have not led to sufficient results. Multiple periods of fixed-term disability pensions are possible. In the earnings-based work pension system, both types of disability pensions can be granted as part-time benefits. When the person reaches statutory retirement age, the disability pension is replaced by an old-age pension.

\section{Predictors}

Predictors for return to the labour market were analysed. Gender was based on national population register information. Data concerning the study subjects' average school grades when leaving basic education at the age of 16 years were gathered from the 1982 register of the Finnish national application system for upper secondary education. School grades vary between 4-10 [2], as regulated by the National Board of Education [3]. The register of Statistics Finland (until 2015) was used to gain information on educational level. The different educational level categories used in the study were based on the International Standard Classification of Education [4]. Basic or below level included early childhood education, primary education, and lower secondary education. Secondary level included upper secondary education and postsecondary non-tertiary education. Tertiary education included short-cycle tertiary education, Bachelor or equivalent level, Master or equivalent level, and doctoral or equivalent level. The register of the Digital and Population Data Services Agency (until June 2016) was used to gain information on having children by the end of the follow-up and marital status at the initiation of the latest disability pension period. We note that cohabiting is not registered and thus cannot be distinguished from our data.

Illness onset, meaning the age of the first occurrence of psychosis for SZ and OP groups and non-psychotic psychiatric disorder for NP, was defined by using the Care Register for Health Care (CRHC), the SII registers of reimbursable medicines, and Finnish outpatient registers. Data on substance use disorders (until 2015) were gathered from the CRHC and outpatient registers and data on the proportion of time spent in psychiatric hospitalization after illness onset (until 2015) from the CRHC from the beginning of the cohort in 1966. The proportion of time spent in psychiatric hospitalization after illness onset was calculated for the time period between the patient's first psychotic episode and the initiation of the latest disability pension period [5]. Information on age at the initiation and length of the latest disability pension periods (in years) until the end of 2016 were gathered using the registers of the Finnish Centre for Pensions (FCP) and the SII.

\section{$\underline{\text { References }}$}

1. Finnish Centre for Pensions (2020) Disability pension, Finland. https://www.etk.fi/en/the-pension-system/pensionsecurity/earnings-related-pension-benefits/disability-pension/. Accessed 21 April 2020 
2. Keskinen E, Marttila R, Koivumaa-Honkanen H, Moilanen K, Keinänen-Kiukaanniemi S, Timonen M, Isohanni M, McGrath J, Miettunen J, Jääskeläinen E (2018) Search for protective factors for psychosis - a population-based sample with special interest in unaffected individuals with parental psychosis. Early Interv Psychiatry 12(5):869-878

3. Isohanni I, Järvelin MR, Jones P, Jokelainen J, Isohanni M (1999) Can excellent school performance be a precursor of schizophrenia? A 28-year follow-up in the Northern Finland 1966 birth cohort. Acta Psychiatr Scand 100(1):1726

4. International Standard Classification of Education (2011) Eurostat ISCED. https://ec.europa.eu/ eurostat/statisticsexplained/index.php/International_Standard_Classification_of_Education_(ISCED). Accessed 21 April 2020

5. Haapea M, Miettunen J, Veijola J, Lauronen E, Tanskanen P, Isohanni M (2007) Non-participation may bias the results of a psychiatric survey: an analysis from the survey including magnetic resonance imaging within the Northern Finland 1966 Birth Cohort. Soc Psychiatry Psychiatr Epidemiol 42(5):403-409 